\title{
Shape memory behavior of nanostructured Ti-Ni alloy
}

\author{
E.P. Ryklina a , S.D. Prokoshkin, A.A. Chernavina
}

Moscow Institute of Steel and Alloys, 4, Leninskiy prospect, Moscow 119049, Russia

\begin{abstract}
The paper focuses on the study of the shape memory effect (SME) and two-way SME (TWSME) in nanostructured Ti-50.7 at.\%Ni alloy. Two different types of structure were studied: nano-subgrain structure (after the moderate deformation with true strain $\mathrm{e}=0.3$ ) and nanocrystalline structure (after the severe plastic deformation with true strain $\mathrm{e}=1.55$ ). The homogenizing annealing at $700 \mathrm{deg}, 20 \mathrm{~min}$ as well served as a reference heat treatment (RHT). In all cases isothermal annealing at 430-450 deg. was performed. The aging time, the initial phase state and external action parameters were varied. The SME training procedure was carried out under a bending mode; the constrained strain $\varepsilon_{\mathrm{t}}$ was varied from 3.9 to $25 \%$ and the loading time from $30 \mathrm{~s}$ to 3 min. Aging time, constrained strain and loading time strongly affect all studied SME and TWSME parameters. The combined effect of $10 \mathrm{~h}$-aging, loading through $\mathrm{B} 2 \rightarrow \mathrm{R} \rightarrow \mathrm{B} 19^{\prime}$ transformation and 15,0 - 17,5\% loading strain bring the highest combination of the recovery strain $\varepsilon_{\mathrm{r}}$ and the two-way shape memory effect $\varepsilon_{\mathrm{TW}}$ in the first training sycle. Multicycle training procedure does not bring significant changes. Variation of training parameters enables additional precise regulation of final functional properties. The obtained results can be used for development elements functioning in conditions of the SME and TWSME manifestation.
\end{abstract}

\section{Introduction}

The functional properties of the shape memory alloys (SMA) strongly depend on the structure, which is defined by thermomechanical pre-history of the material. A post-deformation annealing (PDA) or strain aging after the low-temperature thermomechanical treatment (LTMT) provokes softening processes in the deformed metal: stress relaxation, recovery, polygonization and recrystallization of austenite. In Ti-Ni alloys with nickel concentration more than 50.0at.\% a precipitation process during aging takes place in parallel [1-3]. Therefore, the main factors affecting functional properties in this case are as follows: element concentration changes in matrix; dislocation substructure evolution; formation of oriented internal stress fields caused by nano-size coherent precipitates.

It is worth to acknowledge that the possibilities of the SMA structure regulation by thernonechanical trteatment and its influence on the SMA functional properties are studied properly [1, 4-9].

The regulation of the termomechanical parameters when training, namely, the initial phase state and external action parameters (loading and unloading temperature, load value, loading time, the number of training cycles) open the additional possibilities in properties regulation. This is an object of the present work.

\footnotetext{
a e-mail: ryklina@tmo.misis.ru
}

This is an Open Access article distributed under the terms of the Creative Commons Attribution-Noncommercial License (http://creativecommons.org/licenses/by-nc/3.0/), which permits unrestricted use, distribution, and reproduction in any noncommercial medium, provided the original work is properly cited. 


\section{Experimental}

The Ti-50.7 at.\%Ni alloy having martensitic transformation temperatures $\mathrm{M}_{\mathrm{s}}=-8^{\circ} \mathrm{C}, \mathrm{M}_{\mathrm{f}}=-24^{\circ} \mathrm{C}, \mathrm{A}_{\mathrm{s}}=0^{\circ} \mathrm{C}, \mathrm{A}_{\mathrm{f}}$ $=9^{\circ} \mathrm{C}$ after quenching was studied. LTMT of the initial workpiece (a bar of $2 \mathrm{~mm}$ in diameter) was performed by the warm wire-drawing in several passes with interpass annealings at $700^{\circ} \mathrm{C}(15 \mathrm{~min})$. The wire $0.3 \mathrm{~mm}$ in diameter for the further study was obtained with the accumulated strain of $\mathrm{e}=0.3$ in the last passes without interpass annealings. The wire $0.9 \mathrm{~mm}$ in diameter was subjected to a severe plastic deformation (SPD) by rolling in several passes with the summary true strain $\mathrm{e}=1.55$. As a result, a band with $0,25 \mathrm{~mm}$ in thickness was obtained. The homogenizing annealing at $700^{\circ} \mathrm{C}, 20$ followed by water quenching was chosen as a reference heat treatment (RHT). Aging at $430-450^{\circ} \mathrm{C}$ was performed in all cases. Aging time varied from 10 min to $10 \mathrm{hr}$. The oxidized surface layer was removed by chemical etching in $1 \mathrm{HF}+3 \mathrm{HNO}_{3}+6 \mathrm{H}_{2} \mathrm{O}_{2}$ solution.

The SME/TWSME inducing was performed using "positive" training method by bending the wire samples around cylindrical mandrels of various diameters under two various strain-temperature modes. The Mode 1 included first cooling the sample down to $-196^{\circ} \mathrm{C}$ (B19'- martensite state), then loading with the following exposure under loading, then unloading, then thermocycling in the temperature range from +37 to $-196^{\circ} \mathrm{C}$ for 3 times. The Mode 2 included the following steps: loading at $37^{\circ} \mathrm{C}$ (metastable B2-austenite state), then cooling in a loaded condition to $-196^{\circ} \mathrm{C}$ (i.e. SME/TWSME inducing through $\mathrm{B} 2 \rightarrow \mathrm{R} \rightarrow \mathrm{B} 19^{\text {' }}$ transformation), unloading at this temperature, then thermocycling in the said temperature range for 3 times. The total external strain under loading varied from 3.9 to $25 \%$. The exposure time under loading varied from 30 sec to $3 \mathrm{~min}$.

The induced strain $\varepsilon_{\mathrm{i}}$ was determined at a constraining temperature after unloading. The residual strain $\varepsilon_{\mathrm{f}}$ was determined after heating above $\mathrm{A}_{\mathrm{f}}$ temperature. The recovery strain $\varepsilon_{\mathrm{r}}$ was determined as the difference between $\varepsilon_{\mathrm{i}}$ and $\varepsilon_{\mathrm{f}}$. The recovery elastic strain $\varepsilon_{\mathrm{el}}$ was determined as the difference between $\varepsilon_{\mathrm{t}}$ and $\varepsilon_{\mathrm{i}}$. In this case a possible contribution of superelastic recovery is not separates. The corresponding scheme of determining bending parameters see in $[1$, p.217].

\section{Results and discussion}

LTMT with $\mathrm{e}=0.3$ provokes the nano-subgrain structure formation in $\mathrm{Ti}-\mathrm{Ni}$ alloys after low-temperature PDA $[2,7,8]$. SPD with $\mathrm{e}=1.55$ and further annealing provokes nanocrystalline structure formation with the grain size 25 to $70 \mathrm{~nm}$ in $\mathrm{Ti}-50,7 \% \mathrm{Ni}$ alloy [7]. To determine the optimal aging temperature, the heat treatment in the $350-500^{\circ} \mathrm{C}$ temperature range was performed on the wire samples after said LTMT with the step of $25-30^{\circ} \mathrm{C}$ and aging time $30 \quad$ min, $\quad 1 \quad$ hr $3 \mathrm{hr}$. The measuring of the shape recovery temperature $\mathrm{A}_{\mathrm{f}}$ permits to evaluate the intensity and the depth of the aging process. The temperature $430^{\circ} \mathrm{C}$ brings the most intensive growth of the $A_{f}$ level under the aging time growth (Fig. 1). This result means that verification of strain aging time under isothermal annealing permits the $\mathrm{A}_{\mathrm{s}}-\mathrm{A}_{\mathrm{f}}$ temperatures regulation by means of changing parameters (size and distribution) of $\mathrm{Ti}_{3} \mathrm{Ni}_{4}$ precipitates. This result has permitted to chose the temperature $430^{\circ} \mathrm{C}$ for isothermal annealing.

The effect of total strain $\varepsilon_{t}$ on SME and TWSME parameters was first studied after LTMT and PDA at $430^{\circ} \mathrm{C}, 10 \mathrm{hr}$ (nanosubgrain structure with nano-phase precipitates of $\mathrm{Ti}_{3} \mathrm{Ni}_{4}$ [10].

The evolution of SME/TWSME as a function of total strain under various training modes is presented in Fig. 2.

Deformation of thermally induced martensite (the traditionally used mode 1) brings the maximal level of $\varepsilon_{\mathrm{r}}=7.5 \%$ after $\varepsilon_{\mathrm{t}}=15 \%$ and then drops at $\varepsilon_{\mathrm{t}}=20 \%$ (Fig. 2 a). The elastic recovery strain $\varepsilon_{\mathrm{el}}$ (marked with arrows directed down) increases gradually from $5 \%$ under $\varepsilon_{\mathrm{t}}=15 \%$ and reaches $14 \%$ under $\varepsilon_{\mathrm{t}}=20 \%$. These 
parameters after LTMT do not differ from that after RHT. The TWSME value $\varepsilon_{\mathrm{TW}}$ riches a maximum at $\varepsilon_{\mathrm{t}}=$ $15 \%$ : after RHT $\varepsilon_{\mathrm{TW}}=2.5 \%$ and after LTMT $-1.5 \%$.

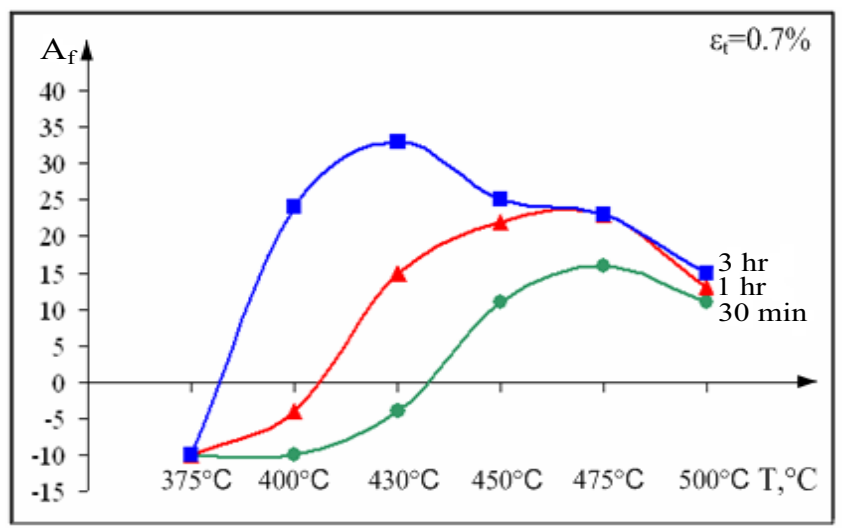

Fig. 1. Development of shape recovery temperature under different aging temperature and aging time

In the case of using the mode 2 (loading "trough R-phase") the total strain increase from 7.5 to 15.0 $17.5 \%$ brings the growth of the recovery strain $\varepsilon_{\mathrm{r}}$ from 5.0 to $14.5 \%$; then it drops to $10 \%$ at $\varepsilon_{\mathrm{t}}=20 \%$. The elastic strain $\varepsilon_{\mathrm{el}}$ increases from $2.5 \%$ at $\varepsilon_{\mathrm{t}}=7.5$ and then drops to $0.5 \%$ at $\varepsilon_{\mathrm{t}}=15 \%$; its value increases then up to $10.5 \%$, when $\varepsilon_{\mathrm{t}}$ increases up to 17.5 while $\varepsilon_{\mathrm{r}}$ stays on the level $14.5 \%$ and reaches the maximum at $\varepsilon_{\mathrm{t}}=15 \%$. LTMT do not bring noticeable changes in studied parameters as compared to RHT. The $\varepsilon_{\mathrm{TW}}$ behavior is analogous to that in the case of the mode 1: it riches the same value after RHT $\varepsilon_{\mathrm{TW}}=2.5 \%$ (at $\varepsilon_{\mathrm{t}}=15 \%$ ); after LTMT it somewhat higher if compare with the mode 1 and amounts $2.0 \%$.

It is important to note that the transform from the traditional training mode to loading "trough R-phase" transformation (with strain aging at $430^{\circ} \mathrm{C}, 10 \mathrm{~h}$ in both cases) brings almost the twice growth of the recovery strain. The abnormally high value $\varepsilon_{\mathrm{r}}=14.5 \%$ exceeds a theoretical resource of the martensitic transformation lattice strain, which amounts about $10.5 \%$ for the studied alloy composition [11].

The shorter aging time $3 \mathrm{hr}$ brings the lower maximum $\varepsilon_{\mathrm{r}}$ value: it is $13.8 \%$ after LTMT and $13.2 \%$ after RHT (see Fig. 2 b). The highest TWSME value $\left(\varepsilon_{\mathrm{TW}}=4.8 \%\right)$ has been measured after $3 \mathrm{~h}$ aging after RHT.

The above described effects need special study, however, we would like to note here that the analogous results were obtained in [13] for single crystals in the same alloy.

The described results permitted to choose the mode 2 for further experiments on nanocrystalline alloy after SPD. The first experiments revealed a problem: loading with $\varepsilon_{t}=8.5-14 \%$ at $45^{\circ} \mathrm{C}\left(5^{\circ} \mathrm{C}\right.$ above the $\mathrm{A}_{\mathrm{f}}$ temperature) was accompanied with a band breaking. Gradual decrease of the loading temperature permitted to chose the temperature $25^{\circ} \mathrm{C}$, which is lower than $\mathrm{T}_{\mathrm{R}}=32^{\circ} \mathrm{C}$; that means that in this case the loading mode 2 could not be completely reproduced: the training procedure was carried through $\mathrm{R} \rightarrow \mathrm{B} 19^{\prime}$ ' transformation.

Figure 3 illustrates the regularities of SME and TWSME evolution under $\varepsilon_{t}$ growth. The behavior of nanocrystalline alloy differs from that of nanosubstructured one. Increasing $\varepsilon_{t}$ from 3.9 to $15.0 \%$ brings gradual growth of recovery strain $\varepsilon_{\mathrm{r}}$ and TWSME value $\varepsilon_{\mathrm{TW}}$. The elastic recovery strain $\varepsilon_{\mathrm{el}}$ is practically absent Up to $\varepsilon_{\mathrm{t}}$ $=8.5 \%$, i.e. all amout of the induced strain is recovered. In the $\varepsilon_{\mathrm{t}}=8.5-15.0 \%$ range the elastic recovery strain increases and reaches $2.5 \%$ at $\varepsilon_{\mathrm{t}}=15.0 \%$. 

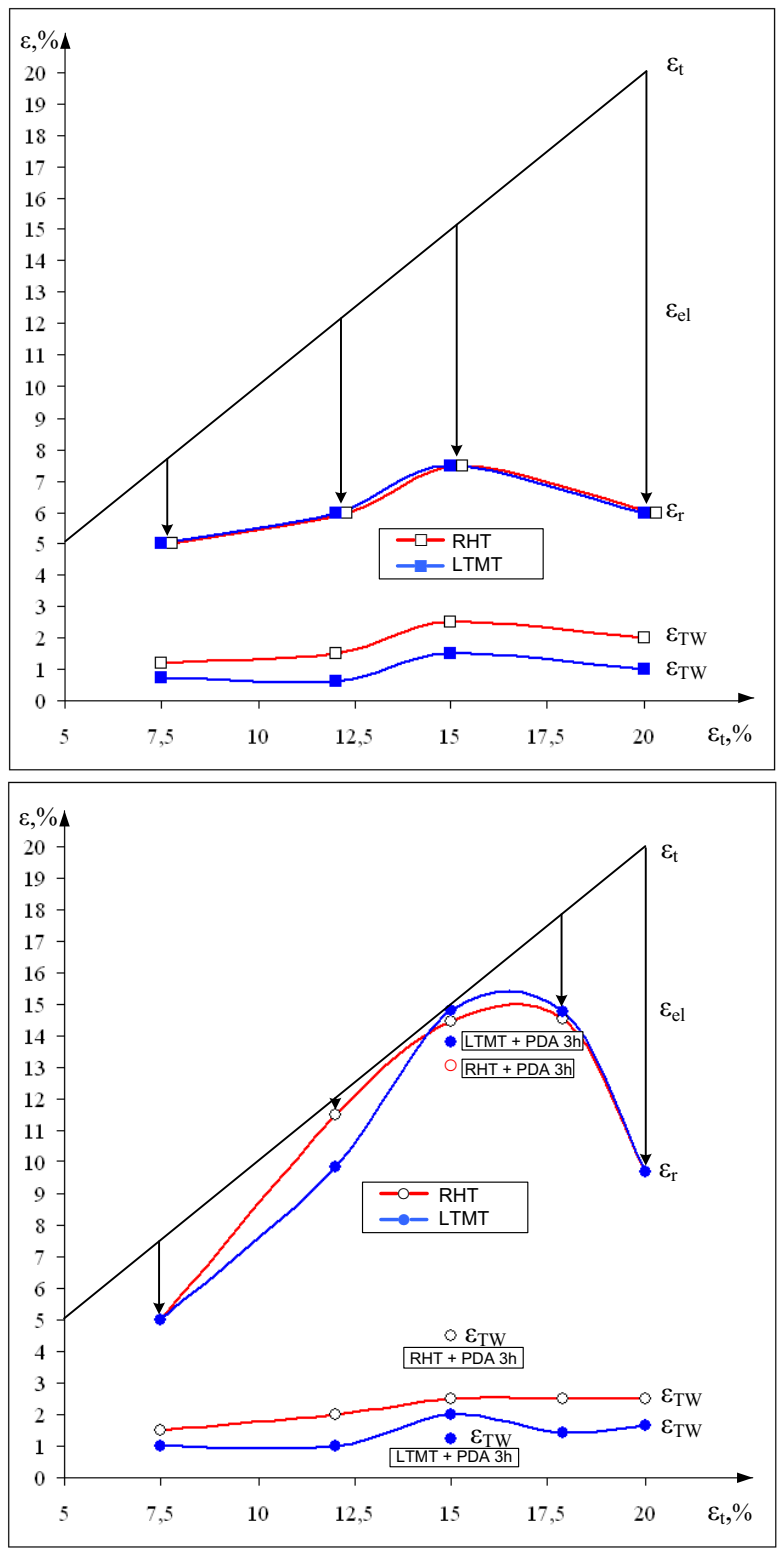

a

b

Fig.2. Effect of total strain on SME/TWSME parameters under different loading modes: a - deformation of martensite (Mode 1); b-deformation through B2 $\rightarrow \mathrm{R} \rightarrow \mathrm{B} 19^{\prime}$ transformation (Mode 2). 

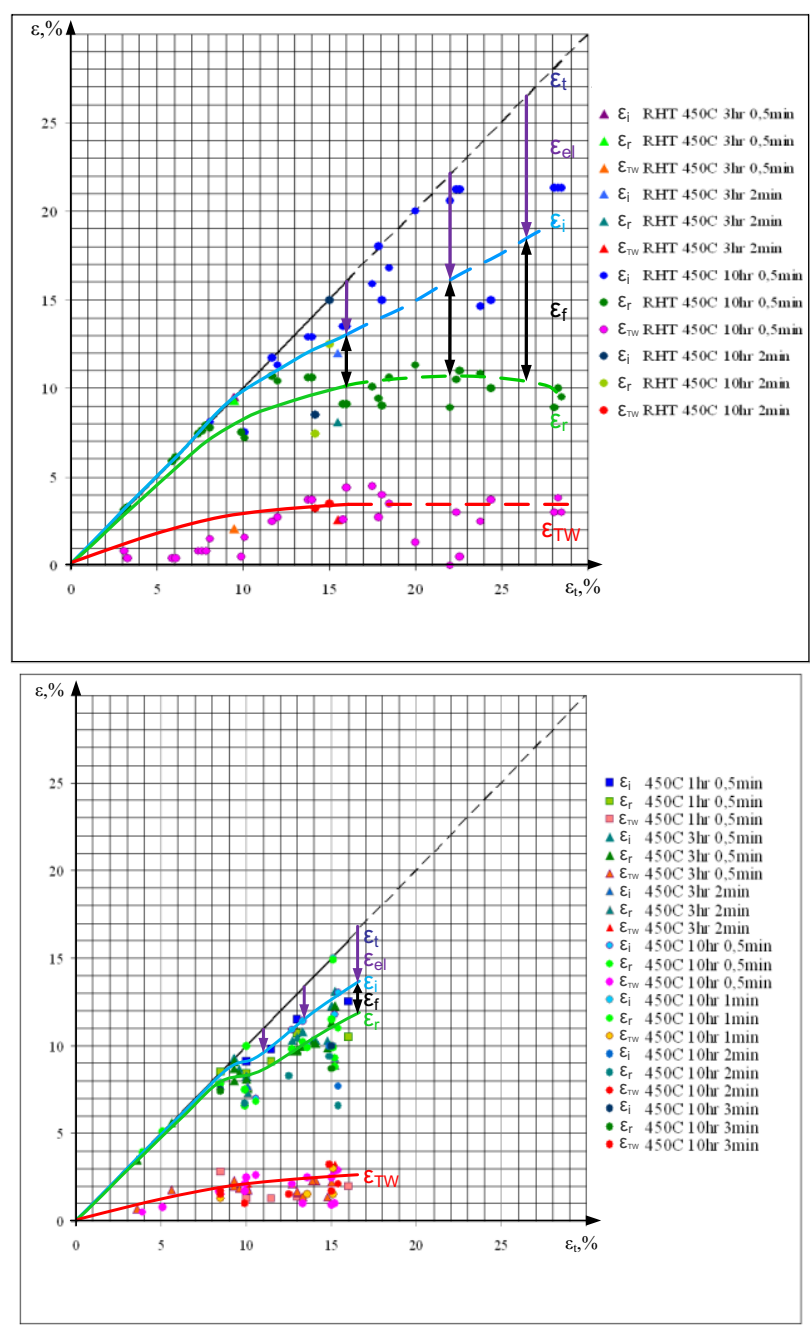

a

Fig. 3. Effect of total strain on SME/TWSME parameters in nanocrystalline alloy under R $\rightarrow$ B19' transformation: a - after RHT; b - after SPD.

Further increasing of the total strain brings material breaking after SPD (Fig. 3b); after RHT material does not break, but the scatter of values increases significantly (dotted line in Fig. 3 a). If compare the studied parameters at $\varepsilon_{\mathrm{t}}=15.0 \%$, one can see that the residual strain $\varepsilon_{\mathrm{f}}=15.0 \%$ after RHT amounts $3 \%$ while after SPD - only $1 \%$ (the length of double-peak arrows between $\varepsilon_{\mathrm{i}}$ - and $\varepsilon_{\mathrm{r}}$ - curves). Aging time after SPD does not bring noticeable changes in the recovery strain; otherwise, the loading time strongly afects $\varepsilon_{\mathrm{r}}$ : its growth from $0.5 \mathrm{~min}$ to 3 min decreases $\varepsilon_{\mathrm{r}}$ value from $11.2 \%$ to $6.5 \%$. 


\section{Conclusions}

1. Simultaneous variation of aging time and thermomechanical external action parameters brings additional possibilities for regulation of SMA functional properties.

2. It is expedient to induce SME/TWSME using two-stage transformation through R-phase under loading: very high value of the recovery strain $(14.5 \%)$ and high TWSME value $(2.5 \%)$ provide their best combination in thermally and thermomechanically treated in Ti-Ni-based alloys after $10 \mathrm{hr}$ aging at $430^{\circ} \mathrm{C}$.

3. The regularities of evolution of SME/TWSME parameters are different in materials with different structure types:

-in nanocrystalline alloy the elastic recovery strain is practically absent after unloading up to 8 ю5\% of a total strain, while it is always present in nanosubstructured and recrystallized materials and drops to minimum at total strain of $15 \%$;

-aging time strongly affects SME/TWSME parameters in nanosubstructured and recrystallized alloys; this influence is insignificant in nanocrystalline alloy.

4. Nanocrystalline structure formed under severe plastic deformation and post0deformation annealing permits reducing of the residual strain by 3 times in comparison to recrystallized structure formed after reference quenching.

This work was carried out under financial support of Federal Program "Research and development in priority directions of scientific-technical complex of Russia 2007 - 2012”, Project № № 2007-3-1.3-25-04-020. The authors are thankful to Prof. V. Brailovski (École de Technologic Supereure, Montréal, Canada) for his help in performing the DSC study.

\section{References}

[1] V. Brailovski, S. Prokoshkin, P. Terriault, F. Trochu. Shape Memory Alloys: Fundamentals, Modeling and Applications. Montreal: ETS Publ., 2003, 851 p.

[2] E.P.Ryklina, S.D. Prokoshkin, I.Yu. Khmelevskaya, A.A. Shakhmina. Mat.Sci.Eng. A 481-482, 134-137 (2008).

[3] J. Khalil-Allafi, G. Eggeler, W. Schmahl, D. Sheptyakov, Mater. Sci. Eng. A438-440, 593 (2007).

[4] V. Brailovski, I.Yu. Khmelevskaya, S.D. Prokoshkin, V.G. Pushin, E.P. Ryklina and R.Z. Valiev, The Physics of Metals and Metallurgy, 97, supple. 1, 3-55 (2004).

[5] S.D. Prokoshkin, S.V. Dobatkin, I.B. Trubitsyna, E.V. Tatyanin, V.V. Stolyarov, E.A. Prokofiev, Acta Mater. 53, 2703-2714 (2005)

[6] E.Ryklina, I. Khmelevskaya, S. Prokoshkin, K. Inaekyan and R. Ipatkin: Mater. Sci. Eng. A 438-440, 1093 (2006).

[7] S.D. Prokoshkin, V. Brailovski, I.Yu. Khmelevskaya, K.E. Inaekyan, V. Demers, S.V. Dobatkin, E.V. Tatyanin, Mater. Sci. Eng. 481-482, 114-118 (2008).

[8] V. Brailovski, S.D. Prokoshkin, K.E. Inaekyan, V. Demers, I.Yu. Khmelevskaya, S.V. Dobatkin, E.V. Tatyanin, Mater. Trans. JIM. 47, 795 - 804 (2006).

[9] A.V. Sergueeva, C. Song, R.Z. Valiev, A.K. Mukherjee, Mater. Sci. Eng. A 339, 159-165 (2003).

[10]: E.P.Ryklina, S.D. Prokoshkin, A.A. Chernavina, N.N. Perevoshchikova, Journal of Functional Materials, 2, No.2, 60-66 (2008) (in Russian).

[11]E. Panchenko, Yu. Chumlyakov, A. Ovsyannikov and M. Tukeeva, Actual Problems of Physical Metallurgy of Steel and Alloys. Ekaterinburg, 2008, p.60 (in Russian). 